\title{
Modelagem Matemática na perspectiva sociocrítica: ambiente para a comunicação dialógica
}

\author{
Mathematical Modeling in the sociocritical perspective: environment for \\ dialogical communication
}

\author{
Silvana Cocco Dalvi \\ Oscar Luiz Teixeira de Rezende \\ Luciano Lessa Lorenzoni
}

\begin{abstract}
Resumo: O presente artigo tem por objetivo refletir sobre a prática da Modelagem Matemática na perspectiva sociocrítica articulada ao modelo de cooperação investigativa que versa sobre a comunicação dialógica. É parte de uma dissertação de mestrado que teve como tema para 0 desenvolvimento da modelagem a escassez de água, problemática que emergiu da realidade dos alunos. A pesquisa é qualitativa, cujos instrumentos usados na produção de dados foram o diário de bordo, produção textual dos alunos e gravações. Os dados foram coletados numa escola localizada em Castelo, Espírito Santo, com alunos do $8^{\circ}$ ano do Ensino Fundamental. Os resultados revelam que a Modelagem Matemática, na perspectiva sociocrítica, é por excelência um ambiente que favorece atos dialógicos; além de aproximar os conteúdos matemáticos de problemas sociais, propicia a investigação coletiva de perspectivas por meio do diálogo,
\end{abstract} favorecendo os processos de ensino e de aprendizagem e a formação cidadã dos estudantes.

Palavras-chave: Modelagem. Comunicação dialógica. Aprendizagem. Formação cidadã.

Abstract: This paper aims to reflect on the practice of Mathematical Modeling in the sociocritical perspective articulated to the model of investigative cooperation that deals with dialogical communication. It is part of a master's thesis whose theme for the development of modeling is water scarcity, a problem that emerged from the students' reality. The research is qualitative whose instruments used in the production of data were the researcher's logbook, students' textual production and recordings. Data were collected at a school located in Castelo, Espírito Santo, with students from the 8th grade of Elementary School. The results reveal that the Mathematical Modeling in the sociocratic perspective is par excellence, an environment that favors dialogical acts; in addition to bringing mathematical content closer to social problems, it promotes the collective investigation of perspectives through dialogue, favoring the teaching and learning process and the citizens' education of students.

Keywords: Modeling. Dialogic communication. Learning. Citizen formation.

Silvana Cocco Dalvi Mestre em Educação em Ciências e Matemática pelo Instituto Federal de Educação, Ciência e Tecnologia do Espírito Santo (IFES). Professora da Secretaria Municipal de Educação de Castelo. Espírito Santo, Brasil.

(iD) orcid.org/0000-0002-4418-023X $\bowtie$ silvanaej@hotmail.com

Oscar Luiz Teixeira de Rezende Doutor em Engenharia Agrícola. Professor do Programa de Pós-Graduação em Educação em Ciências e Matemática do Instituto Federal de Educação, Ciência e Tecnologia do Espirito Santo (IFES). Espírito Santo,

Brasil.

(iD) orcid.org/0000-0001-5591-8562

凶oscar@ifes.edu.br

Luciano Lessa Lorenzoni Doutor em Engenharia Elétrica. Professor do Programa de Pós-Graduação em Educação em Ciências e Matemática do Instituto Federal de Educação, Ciência e Tecnologia do Espirito Santo (IFES). Espirito Santo, Brasil.

D orcid.org/0000-0003-4859-7750 $\triangle$ lucianolessalorenzoni@gmail.com

Recebido em 30/04/2020 Aceito em 22/05/2020

Publicado em 16/06/2020 


\section{Introdução}

A sociedade contemporânea exige cada vez mais indivíduos ativos que, diante das incertezas do dia a dia, se relacionam com o mundo exterior de forma crítica e reflexiva. As constantes transformações em todas as esferas da sociedade é um convite à discussão sobre as práticas pedagógicas que norteiam o ensino de Matemática na atualidade, visto sua forte influência na tomada de decisões das pessoas, empresas e políticas públicas.

Nesse cenário, é pertinente pensar sobre como o ensino de Matemática pode propiciar aos estudantes novos conhecimentos, mas também contribuir na sua formação pessoal, desenvolvendo sua criticidade. Mostrar aos estudantes que a Matemática, enquanto ciência humana, carece de interpretações - e por mais que tenha o argumento definitivo, o modelo matemático que retrata parte de uma realidade —, abarcará determinadas variáveis em detrimento de outras. Ou seja, os estudantes não são neutros de ideologias. Daí a importância de se ater ao ensino de Matemática associado a contextos reais que levem à discussão de problemáticas sociais da contemporaneidade.

Cabe ainda refletir sobre o ambiente escolar pelo qual se dá esse ensino, uma vez que os alunos constituem a sociedade e usam, naturalmente, os conhecimentos adquiridos na escola. Nessa configuração é primordial a construção de uma Educação Matemática emancipadora e democrática, que utiliza-se de práticas que viabilizem o diálogo condizentes a esse fim. Disso emerge a problemática deste estudo: qual a natureza da prática pedagógica que favorece a comunicação dialógica? O diálogo deve nortear os processos de ensino e de aprendizagem de Matemática visto a dar voz aos alunos, conhecendo e debatendo suas perspectivas em relação a aquisição do conhecimento e incertezas da realidade.

Nesse sentido, a Modelagem Matemática, na perspectiva sociocrítica, é uma possibilidade uma vez que prima por temas propostos pelos interesses dos alunos e relacionados ao contexto em que estão inseridos. A natureza dessa atividade é aberta privilegiando a investigação, coleta e organização dos dados. $O$ trabalho em grupo favorece a pesquisa, pois os alunos discutem com seus pares as estratégias usadas na resolução do problema em que investigam.

Outro ponto relevante é a comunicação estabelecida ente os atores envolvidos numa atividade de modelagem matemática sociocrítica que minimiza o discurso burocrático do professor para dar espaço a comunicação cooperativa entre ele e os estudantes. Os processos discursivos ganham certa especificidade mantendo aberto o diálogo; os estudantes são estimulados a 
exercitar o pensamento, verbalizando suas impressões sobre o estudo com a finalidade de expandir coletivamente a arquitetura de seus níveis cognitivos.

Ciente que o processo educativo é complexo e multidimensional, esse estudo limita-se na abordagem de duas de suas dimensões: a natureza da prática pedagógica e a comunicação na sala de aula. Nesse delineamento, com este artigo objetivamos refletir sobre a prática da modelagem matemática na perspectiva sociocrítica articulada ao modelo de cooperação investigativa que versa sobre a comunicação dialógica. A pesquisa é de abordagem qualitativa, cuja prática de modelagem foi desenvolvida com alunos do $8^{\circ}$ ano do Ensino Fundamental.

$\mathrm{Na}$ estrutura do texto, apresentamos os referenciais teóricos referentes à modelagem matemática na perspectiva sociocrítica e no modelo de cooperação investigativa (Modelo Cl). Em seguida, abordamos os procedimentos metodológicos da pesquisa e a descrição e análises da prática de modelagem desenvolvida, a qual teve por desafio responder a indagação: Eu sou gastão de água? Ao final, são apresentadas as considerações. Este artigo é parte de uma pesquisa de mestrado realizada no âmbito do Programa de Pós-Graduação em Educação em Ciências e Matemática do Instituto Federal do Espírito Santo (EDUCIMAT/IFES).

\section{Modelagem matemática na perspectiva sociocrítica}

Biembengut (2003) considera que, desde os tempos mais remotos, o homem já fazia uso da modelagem matemática para resolver problemas do cotidiano e encontrar explicações para os fenômenos da natureza. A autora cita como exemplo dessa relação íntima entre Matemática e realidade, a experiência de Pitágoras (530 a.C.), que, ao esticar um fio ao meio, verificou que vibrava e, repetindo o processo, constatou que a oitava tinha proporção de dois para um. Usando os conhecimentos matemáticos das frações para medir as distâncias das cordas adicionais, ele criou a escala musical usada até os dias atuais

A modelagem matemática dá sentido real ao ensino, pois "Modelagem é um processo rico de encarar situações reais, e culmina com a solução efetiva do problema real e não com a simples resolução formal de um problema artificial" (D'AMBROSIO, 1986, p. 11). Busca-se no cotidiano formas de abordar os conteúdos matemáticos de forma criativa e interessante, possibilitando aos estudantes conhecer aspectos da realidade. Ao discutir problemáticas reais com o olhar da Matemática, os estudantes adquirem argumentos que podem contribuir para mudanças sociais. 
Kaiser e Sriraman (2006) destacam que a modelagem matemática no contexto educacional pode ser desenvolvida com diferentes objetivos, sistematizando seis perspectivas, a saber: a perspectiva realística, que tem o objetivo de resolver problemas aplicados oriundos da indústria ou mercado de trabalho; a contextual, que foca na construção de um modelo matemático previamente construído, levando os alunos a construir ideias matemáticas em situações significativas; a sociocrítica, que considera que a Educação Matemática deve capacitar os estudantes para a reflexão do uso da Matemática na sociedade; a perspectiva epistemológica, que centra-se no desenvolvimento da Matemática enquanto teoria; e a educacional, mais centrada na matematização, em levar os alunos a investigar os modelos matemáticos com um objetivo em si e um meio para a aprendizagem matemática.

Diante das potencialidades da modelagem matemática, essa pesquisa abarca-se na perspectiva da modelagem sociocrítica por caracterizar a natureza da prática desenvolvida em campo. Segundo Jacobini e Wodewotzki (2006), essa perspectiva extrapola os processos de ensino e de aprendizagem dos elementos próprios da Matemática em si. Eles os consideram importantes por estarem presentes na sociedade, mas advertem que devem estar correlacionados aos problemas sociais. Quando se conhece a realidade, o sujeito busca por seus direitos, tornando-se reflexivo e participativo nas ações democráticas que trazem melhorias para a vida comunitária. Nota-se uma preocupação em desenvolver uma consciência crítica nos estudantes por meio da Educação Matemática.

Para Barbosa (2004a), dois pontos são cruciais na prática da modelagem matemática na perspectiva sociocrítica:

- A referência num contexto real — os temas para estudo devem ser extraídos do contexto sociocultural dos alunos. Devem constituir realmente um problema para eles, fazer parte do mundo-vida das pessoas.

- Esquemas não determinados previamente para abordar o problema - como os procedimentos não são fixados de antemão, só os conhecem à medida que os alunos usam sua autonomia e investigam um possível caminho para solucionar o problema. Isso exige esforço intelectual.

Essa natureza "aberta" da modelagem leva à investigação, que é o trajeto para as indagações que se fazem a respeito da problemática em estudo. Aproxima os conteúdos escolares de situações reais do contexto sociocultural dos estudantes e temas de seus interesses. 
Desenvolve a autonomia e criatividade deles visto que precisam usar das ferramentas matemáticas para chegar à uma solução do problema.

$\mathrm{Na}$ atividade de modelagem matemática, na perspectiva sociocrítica, o professor atua como mediador nos processos de ensino e de aprendizagem. Isso significa que ele está atento ao processo investigativo, orientando as estratégias e promovendo discussões quanto a Matemática e sua aplicabilidade, mas também no sentido de conscientizar os alunos sobre como a Matemática influencia a tomada de decisão dos indivíduos e a produção de bens e serviço em todas as esferas da sociedade. Por esse prisma:

\begin{abstract}
0 ambiente de Modelagem está associado à problematização e investigação. 0 primeiro refere-se ao ato de criar perguntas e/ou problemas enquanto que 0 segundo, à busca, seleção, organização e manipulação de informações e reflexão sobre elas. Ambas atividades não são separadas, mas articuladas no processo de envolvimento dos alunos para abordar a atividade proposta. Nela, podem-se levantar questões e realizar investigações que atingem o âmbito do conhecimento reflexivo. (BARBOSA, 2004b, p. 75)
\end{abstract}

Esse ambiente de aprendizagem privilegia os processos interativos dialógicos estimulando o debate, a troca de informações, o levantamento de hipóteses, a busca por soluções e a pesquisa. A aula de Matemática não está pronta no livro didático, mas vai se constituindo a partir dos dados extraídos da realidade, dos questionamentos dos alunos sobre como compreendem o mundo em que estão inseridos. Nessa proposta, a Matemática é usada para desenvolver nos alunos competências democráticas que extrapolam o interior da sala de aula.

Os debates embasados pela Matemática devem mostrar pontos de vista diferentes, variáveis que não foram consideradas, realçar que os modelos matemáticos não são neutros, precisando de interpretações. Os alunos devem ter oportunidade de expressar suas ideias mesmo que, num primeiro momento, não seja satisfatória para o estudo, mas ela serve de apoio para novas discussões e alargamento das apreciações críticas.

Silva e Kato (2012) caracterizam a modelagem matemática na perspectiva sociocrítica quando atendem a um conjunto de quatro categorias: participação ativa dos alunos na construção do modelo, participação ativa do aluno na sociedade, utilização de problema não matemático da realidade e atuação do professor como mediador. Destacam que a modelagem matemática contempla a formação da cidadania dos estudantes, cuja perspectiva sociocrítica é a que mais se identifica com esse propósito.

Dentre alguns obstáculos encontrados pelos professores em desenvolver a prática de 
modelagem matemática está a imposição do cumprimento do currículo escolar que, em muitos casos, ainda mantém a linearidade de conteúdos dissociados da realidade. Em torno desse aspecto, Forner e Malheiros (2019) advogam ser possível trabalhar com a modelagem matemática até mesmo em propostas curriculares "bem fechadas" aproximando-se da resolução de problemas. Eles entendem que o professor, habituado com sua turma, conhece questões de interesses dos alunos, podendo desenvolver a modelagem a partir de situações que fazem parte de seus cotidianos, abrangendo o conteúdo previsto no currículo escolar. Assim, entendem que a modelagem matemática tem potencial para relacionar a Matemática que se processa fora da sala de aula e a do âmbito escolar, visto que sua característica é utilizar-se da Matemática para entender situações não matemáticas do dia a dia.

A seguir, trataremos da comunicação na sala de aula alargando os pressupostos que caracterizam os discursos como dialógicos. Nesse sentido, os processos discursivos são compreendidos como pontos de partida para investigações tanto no que tange a utilização e aplicabilidade das ferramentas matemáticas na resolução de um problema, quanto a reflexões que chegam à formação democrática dos estudantes.

\subsection{0 modelo de cooperação investigativa - Modelo $\mathrm{Cl}$}

Considerando os estudantes como sujeitos protagonistas dos processos de ensino e de aprendizagem, é pertinente se ater ao tipo de comunicação que se estabelece entre professor e alunos na aula de Matemática. Nesse sentido, o discurso de ambos deve propiciar descobertas e investigações contribuindo para a aquisição de novos conhecimentos. Ou seja, a comunicação na sala de aula deve ser dialógica.

Alrø e Skovsmose (2010) afirmam que a comunicação na sala de aula interfere na qualidade da aprendizagem, levando-nos a refletir sobre o absolutismo burocrático que ainda domina muitas aulas de Matemática. Eles elaboraram o que chamaram de modelo de cooperação investigativo, formado por oito atos de comunicação entre os participantes que atuam num diálogo. São eles:

- O estabelecer contato como maneira de criar uma sintonia entre os participantes, prestando atenção nas perspectivas um do outro e às suas contribuições; abrange aspectos emocionais da cooperação investigativa exigindo respeito mútuo, responsabilidade e confiança um nos outros. Os participantes estão dispostos a realizar a 
investigação. Expressões do tipo "É isso?", "Certo?", "Concordam?" mostram 0 relacionamento de parceria e integração entre os envolvidos.

- O perceber perspectivas é um processo de examinar possibilidades, criar hipótese, manter a curiosidade. Significa perceber as relações que 0 estudante está fazendo com 0 problema, o modo como ele está entendendo a questão expressando suas perspectivas, mesmo sem ter certeza de sua validade. Questões hipotéticas podem dar novos rumos à investigação. "O que acontece se" usarmos esse ou outro procedimento, ou esse cálculo, ou essa expressão, ou essa figura, ou [...]. Assim, as propostas vão sendo ampliadas e elucidadas. Os estudantes assumem a condução do processo investigativo procurando descobrir o que ainda não sabem ou pensam não saber. Entretanto, é natural que, no cenário investigativo, perspectivas interessantes não sejam notadas pelo grupo, passando despercebidas, e uma "autoridade" seja necessária para destacar uma ideia particular referente à situação.

- Depois de perceber uma perspectiva de forma colaborativa, ela será reconhecida e conhecida pelo grupo. É um esforço de matematizar a situação em que as propostas poderão ser reformuladas e aprofundadas. Consiste em delinear as ideias matemáticas e a realização das "questões-por-quê" que surgem da curiosidade das "questões-o-queacontece-se". Rejeitar suas ideias sem argumentação indica insegurança.

- $O$ ato de posicionar-se está relacionado ao de compartilhar o que se sabe, expressar o que pensa estando receptivo às argumentações de seu posicionamento. Os vários argumentos ajudam a tornar mais nítida uma perspectiva comum que está sendo construída com a participação de todos. As declarações do tipo "Não compreendi", "Entendi de outra forma", "Certo?", "Não acha isso?" revelam que a comunicação está ocorrendo não na tentativa de defender um ponto de vista porque ele é pessoal, mas de torna-lo público para ser analisado e questionado se deve ser aceito ou rejeitado.

- O pensar alto torna o pensamento público. Defender posições pensando alto permite que as perspectivas sejam conhecidas por todos. É uma conversação em que os participantes examinam e descrevem seus pressupostos sobre a questão.

- Reformular significa repetir o que já foi dito do seu jeito. É um parafrasear elucidando o processo argumentativo. Os participantes confirmam o entendimento de uma perspectiva comum ou eliminam dúvidas ainda existentes no processo de investigação. Essas 
questões de conferência são importantes para averiguar se de fato há compreensão. 0 ato de reformular e pensar alto está relacionado à situação de completar meias-falas.

- Desafiar significa tentar ver as coisas em outro sentido. Uma questão hipotética ou uma questão associada - "O que acontece se..." - pode desencadear uma proposta alternativa levando ao exame de novas possibilidades. Uma precondição para desafiar 0 estudante é o esclarecimento de perspectivas dando sugestões investigativas. O desafio é bem-sucedido quando os participantes o compreendem.

- O avaliar as perspectivas faz parte de todo processo investigativo e é feito por estudantes e professor. Eles enxergam o mesmo problema? Resolvem da mesma forma? O objetivo não está centrado apenas em achar a perspectiva "correta", mas chegar a um mesmo denominador. "A questão de que está 'certo' ou 'errado' não pode prevalecer no processo de investigação" (ALRØ e SKOVSMOSE, 2010, p. 72). Avaliar é dar um feedback construtivo.

De acordo com esses autores, dialogar não é qualquer ato da fala, mas discursos com características especiais, por meio dos quais é possível construir algo em conjunto. Consideram que os elementos do Modelo $\mathrm{Cl}$ constituem atos dialógicos, pois envolvem a realização de uma investigação colaborativa. As qualidades de comunicação associadas ao diálogo permitem a participação ativa dos estudantes, que assumem o processo de investigação em busca do conhecimento de forma coletiva e respeitosa aos integrantes do grupo escolar a que pertencem. Acostumados a esse ambiente, terão mais chances de exercer na sociedade a cidadania.

\section{Procedimentos metodológicos}

A pesquisa é de abordagem qualitativa, na qual procurou-se retratar as experiências vivenciadas, as discussões e apreensões dos estudantes durante o desenvolvimento da prática de modelagem na perspectiva sociocrítica. No entendimento de Minayo (2003), "a pesquisa qualitativa se preocupa com um nível de realidade que não pode ser quantificado. Trabalha com o universo de significados, aspirações, crenças [...] que não podem ser reduzidos à operacionalização de variáveis" (p. 22). A investigação foi realizada em uma escola pública da rede municipal de Castelo, Espírito Santo, com 18 alunos do $8^{\circ}$ ano do Ensino Fundamental.

Os instrumentos usados na produção de dados foram o diário de bordo do pesquisador, 
que segundo Minayo (2003) é um "amigo silencioso", em que o pesquisador coloca suas percepções, angústias, questionamentos, tornando-se um diário pessoal e intransferível; o diário do bordo dos estudantes para que também eles registrassem acontecimentos importantes do trabalho investigativo e realizassem suas produções textuais; e as gravações em áudio usadas nas transcrições dos discursos.

As análises dos dados produzidos em campo são feitas à luz do referencial teórico confrontando a teoria com a prática, elucidando as hipóteses e interpretando os resultados.

\section{Descrição e análise dos dados}

O tema para a atividade da modelagem surge pela indagação do pesquisador/professor em saber dos estudantes uma situação que os incomodavam. Nesse sentido, eles relataram a preocupação com a escassez de água, um problema socioambiental vivenciado, para o qual foi necessário racionar a distribuição de água; o "carro de som" nas ruas alertava sobre o desperdício com lavagem de calçadas e carros e o rio que "corta" a cidade praticamente secou. Diante do interesse dos estudantes, vislumbrou-se a possibilidade de desenvolver uma atividade de modelagem matemática na perspectiva sociocrítica a partir desse tema, de referência num contexto real e aparentemente um problema não matemático (ARAÚJO, 2007).

Na sequência, o pesquisador/professor exibiu a reportagem Água, planeta em crise ${ }^{1}$, que trata do problema da crise hídrica no Brasil e em outros países. Após assistirem a reportagem, foi feito um momento de discussões. Segundo Barbosa (2007) é aconselhável que num ambiente de modelagem sociocrítica os alunos se envolvam nas discussões do tema. Assim, é possível conhecer suas interpretações e perspectivas indicando os possíveis caminhos nos quais 0 professor pode atuar como mediador da prática educativa.

Apresentamos, na Interação 1, as discussões com os estudantes sobre o tema. A fim de evitarmos sua personalização, identificamos com a letra $A$, acompanhado de um número, 0 pesquisador/professor pela letra $P$ e 0 grupo de alunos pela letra $G$ quando não foi possível identificar a fala de um único aluno.

\footnotetext{
${ }^{1}$ Esta reportagem é encontrada no site do Jornal da Globo, da Rede Globo de televisão, em http://g1.globo.com/jornalda-globo/noticia/2015/09/veja-cinco-reportagens-da-serie-agua-planeta-em-crise-do-jg.html.
} 
Interação 1 - Os alunos discutem a abrangência e importância do tema

$P$ : Vocês acham importante estudar o consumo de água?

G: Sim.

A10: A água é muito importante pra gente, porque, se a gente for deixando com o tempo, vamos ficar sem água.

P: Vocês concordam com ideia dela? G: Sim.

A05: Eu concordo.

P: Então vocês acham importante estudar esse assunto aqui na escola?

A13: Mas não só na escola, como em outros locais, porque [tipo], se for estudar só na escola, as pessoas que estão na escola vão ter essa consciência, mas os outros não [...]. Se a gente não tiver água [tipo assim], a gente não sobrevive, a gente precisa de água.

P: Você está colocando, então, que o assunto é importante e deve ser estudado na escola e também em outros locais fora da escola. É isso?

A13: É.[...]

A10:A gente 'tá vendo que a água tá acabando, nossas florestas estão acabando... A gente até vê, mas não corre atrás pra cuidar. Algumas pessoas até correm, mas a maioria sabe [sabe do problema] e não consegue correr atrás.

P: A10 levantou uma situação muito séria. Nós sabemos que a água está acabando, mas não tomamos uma...

G: (alguns alunos interrompem a fala e completam) uma atitude.

$P:$ É como se nós ficássemos [vê se é isso, A10] assistindo, parados!

A10: Isso! A gente se faz de cego. A gente vê mas se faz de cego.

P: Alguém quer complementar a fala dela? Pode falar!

A02: As pessoas pensam que tem bem mais pessoas fazendo economia de água e não colaboram. Se elas estão fazendo, não precisa eu fazer também. Eu posso parar de fazer, nem preciso fazer, que tem mais gente fazendo. Vai ter água do mesmo jeito!

A12: Acham que porque só uma pessoa tá ajudando a não acabar com a água vai resolver! Tem que ter mais que uma pessoa. Uma só não vai... não vai...

Observa-se, na Interação 1, que se está promovendo um ambiente de aprendizagem marcado pelo diálogo. Os envolvidos no discurso trabalham coletivamente, buscando uma perspectiva comum em torno do problema em estudo. Vários são os indícios de que os atos dialógicos estão presentes no discurso.

O estabelecer contato é diagnosticado na sintonia entre os participantes, um prestando atenção no outro, num clima de harmonia. O perceber é identificado quando os estudantes expõem suas perspectivas para serem examinadas como nas falas de $A 10, A 13, A 12$ e $A 02$, que verbalizam o que pensam sobre a questão sem medo de retaliações. A perspectiva de que cada um tem que fazer a sua parte é então reconhecida. Os estudantes se posicionam compartilhando seus pontos de vista. 
O pensar alto acontece quando tornam público seus pensamentos, ideias e sentimentos durante a investigação. 0 reformular e desafiar estão muito presentes nos discursos do professor, que parafraseia as perspectivas levantadas pelos estudantes, certificando-se de que eles estão compreendendo a discussão e desafia-os reexaminando as possibilidades, como fica evidenciado no questionamento: se o assunto deve ser estudado só na escola ou não. $O$ avaliar é feito não só pelos alunos, quando concordam com as perspectivas que surgiram nos discursos, mas também pelo professor em forma de elogio.

O ato de avaliar as perspectivas caminha no sentido não do certo ou do errado, mas no da construção de um ponto comum para o processo investigativo. Para Alrø e Skovsmose (2010), é fundamental o envolvimento dos estudantes no diálogo, visto por eles como um processo investigativo imprevisível. Nota-se, na Interação 1, suas participações, produzindo discursos de forma espontânea sem ter fixado a priori nenhuma perspectiva. A conclusão de que cada um tem de fazer a sua parte economizando água é feita dentro de ambiente de pesquisa, sendo imprevisível a perspectiva a ser construída pelos estudantes.

Eles também discutiram alguns dados numéricos contidos na reportagem, mas passam as reflexões, saindo das informações globais, para o consumo de água no município tomando consciência que também estão inseridos nesse problema, conforme é discriminado na Interação 2 a seguir:

Interação 02 - As discussões ganham espaço local

A10: A água é mal distribuída igual tem umas pessoas que usam o máximo que pode, tem um controle pra poder sobreviver. Já há algumas pessoas que consegue ter bastante água. Em Castelo eu acho que não falta água, a gente usa o que a gente não precisa, a gente usa mais do necessário a nossa sobrevivência.

$P$ : A10 trouxe a discussão do consumo de água para nossa cidade, trouxe a questão para Castelo. Vocês acham que nós castelenses usamos a água de forma consciente? G: Não.

A03: Tem gente que lava carro todo dia!

P: Espera aí! Esse "não" não foi unânime? Todos responderam não?

A13: Nem sempre, professora. Algum ser humano deve salvar Castelo (referindo-se que nem todos os castelenses desperdiçam água).

A02: Eu 'tava vindo pra escola com o Rafael [aí tipo] tem um lugar que tava saindo água da calçada, assim, aí eu vi uma mulher que tava lavando a calçada. Eu pensei: não é possível!!! Um monte de gente fala que não pode lavar a calçada, mas não tem jeito não.

$P$ : Então, deixa eu reformular minha colocação: nós castelenses, a maior parte de nós, usamos a água de forma consciente? 
G: Não.

Notamos, no discurso da Iteração 2, que a Matemática é usada para desenvolver competência crítica e compromisso social nos estudantes. A10, em seu discurso, mostra ter consciência de que há um desperdício de água em Castelo, quando diz que "usamos mais água do que precisamos para nossa sobrevivência"; A02 relata a ação de uma mulher lavando a calçada e sua indignação, quando diz "mas não tem jeito não". Entendemos que essa atitude não é de quem usa a água de forma racional. Essas são preocupações discutidas por Skovsmose (2014) quando fala da Educação Matemática crítica.

Algumas controvérsias surgiram nesse diálogo. O professor notou que, ao tentar elucidar a perspectiva de $\mathrm{A} 10$, a classe não estava de comum acordo e $\mathrm{A} 13$ se posiciona defendendo seu ponto de vista e argumentando que deve ter algum castelense que não desperdiça água. Isso faz com que o professor reveja sua colocação, reformulando-a. $O$ ato de avaliar as perspectivas que afloram nessa interação feito pelo professor acontece como um feedback construtivo, para que ele continue examinando as possibilidades para dar sequência a investigação. Avaliar é um ato dialógico que pode ser feito tanto pelo professor quanto pelos alunos.

Alrø e Skovsmose (2010) consideram que dialogar é realizar uma investigação correndo riscos, ou seja, essa investigação é imprevisível. Na Interação 2, os estudantes estão abertos à investigação, assumindo diferentes posicionamentos em relação ao uso da água em Castelo. As perspectivas surgem de um processo compartilhado em busca do conhecimento.

Dando continuidade às interações anteriores, os estudantes falam da sua relação direta com o uso da água, conforme observa-se na Interação 3.

\section{Interação 3-Os alunos falam da sua relação com o problema em estudo}

A14: A gente 'tá com água e não estamos nem aí para os que não têm.

P: Nós não estamos nem aí para o que está acontecendo. É isso?

A05: É.

A12: A gente gasta...

A09: A gente não se preocupa enquanto a gente tem aqui. A gente só se preocupa quando a gente não tiver. Entendeu?

A12: Só quando chegar o nosso dia...

A18: Quando a gente tem a água, a gente não se preocupa.

$A 07: E$, quando a gente não tem água...

A15: A gente sabe que ela está acabando, mas a gente não se preocupa. 


\section{A16: A gente sabe que vamos ficar sem água!}

A14: Que, quando a gente tem água, a gente não 'tá ligando pra quem não tem, né? A gente 'tá usando do jeito que a gente quer!

Nessa interação, identifica-se os atos dialógicos de estabelecer contato nos discursos dos estudantes que se apoiam reciprocamente na perspectiva levantada por A14. Essa perspectiva é percebida pelos demais estudantes participantes do diálogo que se aproximam e insistem nesse assunto, examinando-a, levando-os a reconhecer que, enquanto eles têm água, gastam à vontade, sem se preocupar em economizá-la, mas que um dia pode faltar. Os posicionamentos desses estudantes indicam que estão a favor da ideia expressa por A14. O pensar alto os leva a olhar para dentro de si mesmos, para as próprias ações, usando a água, como fica evidenciado no discurso de A12: "A gente gasta...". A comunicação dialógica estabelecida recai sobre a crise e conflitos da sociedade atual; nesse caso, a escassez de água.

As interações apresentadas até o momento - Interação 1, Interação 2 e Interação 3 dizem respeito à problemática da escassez de água numa perspectiva da vida em sociedade $\mathrm{e}$ são importantes num trabalho embasado pela Educação Matemática crítica. De acordo com Barbosa (2003), mais do que informar matematicamente, é preciso educar criticamente por meio da Matemática, o que implica preparar os estudantes para a cidadania. A escola torna-se uma extensão do contexto social dos estudantes. Assim, criamos condições para que eles desenvolvam competência democrática. Na sequência pesquisador/professor os desafia a enxergar o problema não matemático trazido com o olhar da Matemática, conforme apresentamos na Interação 4.

Interacão 4 - 0 problema da escassez de áqua é visto com o olhar da matemática

$P$ : $O$ que podemos estudar matematicamente com esse assunto? [...]

A11: A distribuição da água fazendo um infográfico.

A1: A porcentagem de água gasta em alguns lugares e cidades, comparando com outros lugares.

A13: Fazer uma pesquisa dentro ou fora da escola e depois fazer gráficos [tipo assim] gráficos e porcentagem.

A07: [Tipo] Podemos trabalhar come eles e depois produzir um cartaz ou alguma coisa.

A10: Fazer uma pesquisa em todas as escolas de Castelo sobre o consumo de água. Ver se a água é tratada ou é de esgoto, se tem pessoas que passam sede. Mostrar a realidade do nosso mundo tornando isso visível para todos.

P: Ok! Vocês estão delimitando esse tema que é imenso. Mais alguém?

A12: A quantidade de pessoas no mundo e a quantidade de água que cada uma utiliza em lugares com muita escassez de água e em lugares com muita água chegando a uma diferença.

P: Muito bom! 
A17: Um gráfico com o número de pessoas que gastam água em comparação ao número de pessoas que economizam.

A02: Fazer uma pesquisa com especialista para ver quanto tempo ainda temos água e o que cada um tem que poupar antes dela acabar.

$P$ : O que você entende, $A 02$, por poupar?

A02: Cuidar da água, fazer as coisas gastando menos.

P: Joia! Muito bom!

A18: Todo mundo poderia trazer a conta de água pra ver o que cada um gasta.

Identificamos, na Interação 4, que o Modelo $\mathrm{Cl}$ marca os discursos num processo comunicativo investigativo, em que o professor propicia aos estudantes verbalizar como poderia ser feito um trabalho com o tema, usando os conhecimentos matemáticos. Nenhuma atividade no campo específico da Matemática é imposta aos estudantes. O professor estimula a investigação de perspectivas quando diz: "Ok! Vocês estão delimitando esse tema que é imenso. Mais alguém?". Eles entendem o desafio e apontam suas sugestões. Professor e estudantes se comunicam de forma cooperativa, tratando, agora, o tema numa abordagem dos conteúdos matemáticos.

As várias sugestões de encaminhamentos matemáticos dados pelos estudantes nos dão indícios de seus envolvimentos, contribuindo para um cenário investigativo. Suas perspectivas são vistas como ponto de partida para a continuidade das investigações e usadas como instrumentos para novas aprendizagens.

Os diálogos envolvendo a problemática da escassez de água ajudou 0 pesquisador/professor a descobrir o modo de pensar dos estudantes em relação ao tema e a elaborar a questão desafiadora - Eu sou gastão de água? -, que consistia em que cada estudante medisse o seu consumo diário de água. Esse desafio não se enquadra no paradigma do exercício sugerindo várias respostas individuais, pois dificilmente eles consomem a mesma quantidade diária de água. As informações necessárias para responder ao desafio não estão contempladas em seu enunciado exigindo que busquem essas informações pesquisando o próprio consumo de água.

A questão desafiadora elaborada com base nas discussões do tema sugere que, no desenrolar do trabalho matemático de medição, a questão socioambiental da escassez de água seja discutida mais profundamente. Não há exposição de conteúdos pelo professor, mas suas propriedades serão exploradas conforme a investigação é realizada, o que dá ao desafio um caráter de imprevisibilidade. Nenhum procedimento de como realizar a coleta de informações 
sobre o consumo diário de água foi definido a priori.

Para Barbosa (2004a), esse é um ponto crucial na prática da modelagem sociocrítica: não possuir esquemas prévios para abordar o problema, os quais somente são conhecidos à medida que os estudantes fazem a investigação, exigindo deles um esforço intelectual. Nesse ambiente de modelagem, eles vão usar os conceitos e algoritmos matemáticos para abordar o tema.

De acordo com as anotações feitas no diário de bordo do pesquisador, os estudantes necessitam de um tempo da aula para dialogar sobre como procederiam para fazer essa medição. O pesquisador/professor, enquanto circulava entre os estudantes, observava que eles trocavam informações, discutiam alternativas, examinavam e selecionavam estratégias que julgavam pertinentes, para encontrar um caminho matemático que satisfizesse a questão desafiadora.

Skovsmose (2014) compara o momento em que um cenário investigativo é apresentado aos estudantes com um momento de abertura de possibilidades de sentidos, como o requerido em atividades de pesquisa, que manifestam o envolvimento e interesse do pesquisador, remetendo à questão da intencionalidade. Os estudantes estavam dispostos a realizar a pesquisa com a intenção de responder ao questionamento: Eu sou gastão de água? Como nenhuma estratégia de medição foi definida pelo professor, eles se encarregaram de descobrir por si mesmos, no diálogo em grupo, possíveis caminhos a serem explorados.

Depois de um certo tempo, o pesquisador/professor perguntou novamente se seria possível, ou não, realizar a medição, e os estudantes disseram que "sim". O convite ao cenário investigativo foi aceito, considerando o "sim" deles e o protagonismo na busca de um procedimento para fazer a medição. Entendemos que o diálogo entre eles fomentou as investigações.

Combinou-se que essa medição seria feita em casa, na realidade de cada um. Esta é uma característica da modelagem: buscar os dados para estudo em fontes reais extraídos do contexto sociocultural dos estudantes. Os procedimentos e resultados das medições só foram conhecidos na aula seguinte quando eles explicaram suas estratégias e os resultados obtidos.

Foi disponibilizado a cada estudante um pequeno caderno, para que anotassem as estratégias utilizadas na medição e a quantidade de água consumida por eles durante um dia. $\mathrm{A}$ esse caderno denominou-se diário de bordo do estudante, em que identificamos três procedimentos distintos de medição, a saber:

Um grupo pesquisou na internet a quantidade de água gasta por minuto em cada atividade 
em que usava água. Marcava o tempo de consumo e depois multiplicava pelo valor pesquisado somando os resultados, obtendo o consumo diário de água. Na Interação 5, apresentamos essa estratégia.

Interação 5 - Estratégia de medição do consumo diário de água usando a garrafa PET, a pesquisa na internet e o celular

A06: Eu fui olhando na internet e marcando o tempo no celular e fazendo as anotações. Depois juntei tudo e deu 190,6 litros (risos de surpresa).

P: Os valores que estavam na internet são mais ou menos o tempo em que você consome água ou não?

A06: Não. Lá estava em minutos e eu fui ajeitando.

P: Essa estratégia dá um resultado para cada pessoa, não é mesmo? Cada um fica um tempo no banho, com a torneira aberta...

A10: Eu pedi ajuda a minha mãe. Tinha vez que passava um pouco de um minuto ou faltava um pouco, então eu arredondei para facilitar os cálculos. Lá tinha descarga que gastava 6 litros ou 9 litros e então eu perguntei minha mãe qual era a nossa e ela disse que não tinha trocado, era a de 9 litros. Coloquei um litro na geladeira. No final sobrou uns quatro dedos no litro. Ixi! Bebi menos de um litro.

P: Cuidado com a saúde! Já discutimos que devemos beber pelo menos dois litros de água por dia, né?

A10: É! Eu fiz durante um dia e deu 475 litros, fiz durante uma semana e deu

3.325 litros, durante um mês de 31 dias que deu 14.250 litros e de 31 dias que deu 14.725 litros.

P: Gente, estou orgulhosa de vocês. Mas é muita água! (risos de admiração do consumo).

Na Figura 1, expomos o registro de um dos estudantes que usou essa estratégia. Em sua pesquisa na internet, considerou que um banho de cinco minutos consome 45 litros; a pia do banheiro, nove litros por minuto; e a pia da cozinha 117 litros em 15 minutos. As ações registradas foram dois banhos de dez minutos cada um, seis minutos com a torneira da pia do banheiro aberta, cinco descargas consumindo nove litros cada uma, 25 minutos usando a torneira da cozinha e um litro de água que foi ingerido. Em seguida, A10 calculou seu consumo em uma semana e um mês com 30 e 31 dias. 


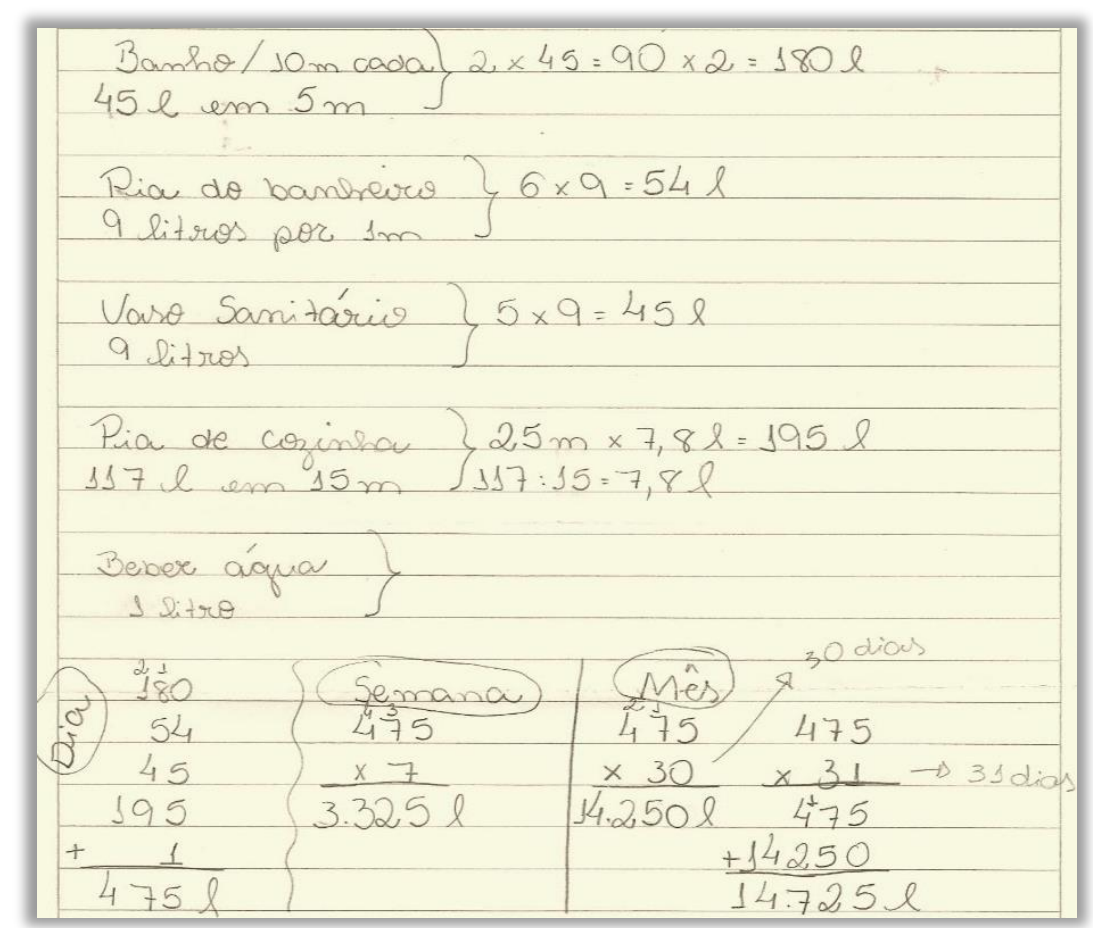

Figura 1: Estratégia de medição do consumo de água feita por A10

Destaca-se, na Interação 5, o ato dialógico de reformular, quando A10 ouve as perspectivas de A06 e faz um parafrasear mais detalhado sobre a estratégia de medição usada. A10 explica o que A06 chamou de ajeitando, como fazer um arredondamento para o minuto com a intenção de facilitar os cálculos. Relata a dúvida que teve com o consumo da descarga. Notamos que $A 10$, com base no discurso de $A 06$, faz uma conferência dos procedimentos usados na medição e, em seguida, esmiúça que fez os cálculos do consumo de um dia, uma semana e um mês, considerando 30 e 31 dias.

No discurso do professor - Interação 5 -, ele tem dúvida de como o tempo de consumo é apresentado na internet, indagando A06, pois não sabia que conduziriam a medição por esse caminho. O relato de A06 suscita a curiosidade em saber como lidaram com as unidades padrões de tempo. Ao perceber a estratégia adotada, busca investigá-la procurando elucidá-la. O professor é um integrante do diálogo que participa com os estudantes na construção de uma perspectiva, para medir o consumo de água. No último discurso, avalia os estudantes com um elogio.

Nos demais discursos, o professor trata de questões que são preocupações da Educação Matemática crítica quando diz: "Essa estratégia dá um resultado para cada pessoa, não é mesmo? Cada um fica um tempo no banho, com a torneira aberta...", mostrando aos estudantes que a investigação levou a várias respostas corretas para um único problema inicial. Em outra fala - 
"Cuidado com a saúde! Já discutimos que devemos beber pelo menos dois litros de água por dia, né?" - , alerta sobre a importância da ingestão de água para a saúde e, na última - "Mas é muita água!" (risos de admiração do consumo) —, o consumo exagerado de água, que também é reconhecido pelos estudantes com seus risos de admiração.

Outro grupo de alunos priorizou os baldes e garrafas PET, mas sentiram necessidade de pesquisar na internet. Na Interação 6, continuidade do diálogo anterior, apresentamos como os estudantes encaminharam as medições.

\section{Interação 6 - Estratégia de medição do consumo diário de água com baldes, garrafa PET e em pesquisa na internet \\ $P:$ Alguém fez diferente?}

A12: Eu. Na hora do banho eu peguei baldes e fui calculando. Pra escovar os dentes eu enchi uns litros e ia usando a água do litro. Pra lavar o rosto, usei a água do litro também. Na hora de beber água, bebi por litro. Mas na descarga não deu. Aí entrei na internet e vi que uma descarga gastava mais ou menos 20 litros e multipliquei pelo tanto de vezes que eu dava descarga.

$P$ : Entendi. E quanto que deu em tudo?

A12: 362,5 litros.

A07: Eu tentei usar um litro para escovar os dentes, mas não deu certo; então, eu aproximei. Em tudo deu 94 litros e meio.

P: Mais alguém?

A04: Eu peguei um balde e fui enchendo os litros e ia esvaziando e vendo quantos litros gastava nas coisas. Mas, na descarga e no banho, ficou difícil fazer assim. Aí pesquisei na internet também. Deu 393 litros por dia.

$P$ : Está certo! Muito legal, gente!

Na Figura 2, mostramos como A12 particionou o seu consumo de água. Os baldes de água usados no banho estão em litros e, para o consumo da descarga, considerou três descargas durante um dia, gastando 20 litros em cada uma, totalizando 60 litros.

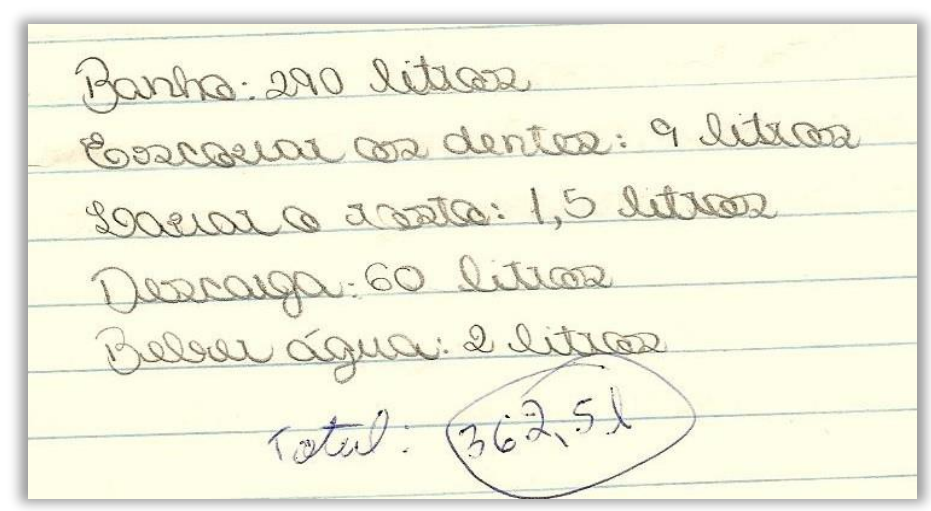

Figura 2: Estratégia de medição do consumo diário de água feita por A12 
Nota-se, na Interação 7, que A12 pensa alto expondo sua estratégia para ser reconhecida pelos grupos com segurança. A07 e A04 compartilham da mesma perspectiva de A12 e relatam as dificuldades e soluções que encontraram na medição. Eles avaliam o procedimento adotado. O estabelecer contato, prestando atenção nas perspectivas que surgem do processo de medição, auxilia na continuidade das investigações. Os estudantes se entendem e se respeitam, estando abertos a novas estratégias para medir o consumo diário de água.

Outro grupo de estudantes usou como estratégia a conta de água. Na Interação 7, apresentamos esta discussão.

\section{Interação 7 - Estratégia de medicão usando a conta de água}

A17: Eu peguei a conta de água e dividi 16.000 por três porque vem o [consumo] da minha casa, da casa do meu tio e da minha vó, depois fiz algumas contas distribuindo o consumo para dar o total.

P: E aí você chegou em quantos? A17: Num dia, 533 litros.

P: Tá. Alguém mais usou a conta de água?

A15: Eu usei a conta de água do mês passado. Aí 'tava lá 23.000 litros e eu peguei e dividi por 30 dias que é um mês e depois por quatro pessoas, que aí eu acho que está errado, mas deu 191,666 litros. Eu acho que o meu está errado! De todo mundo está dando mais de 200 litros e o meu deu 190 litros e poucos.

P: Turma o que vocês acham que pode estar errado no modelo de A15? A03: 0 dela é uma média e não o que cada um gasta. Não é o consumo de cada um.

A10: Cada pessoa não gasta a mesma quantidade de água; então, na conta vai 'tá' uma coisa de todo mundo, da família. Não vai conseguir saber o de cada um.

P: Muito bom, gente! Pessoal, vocês entenderam o que eles explicaram?

G: Sim.

A17: O dela está parecido com o meu, mas... o meu deu mais quantidade de litros que 0 dela.

P: Você dividiu o consumo pelo número de pessoas?

A17: É!!! Na verdade não. Dividi pelas três casas do prédio para saber o consumo só da minha casa (Muita discussão no grupo).

G: A17 usou casa e A15 pessoas.

A17: É! Tá certo. O que eu achei foi a média de cada casa, e não de cada pessoa

Na Figura 3, mostramos que o aluno A15 observou o consumo de água mensal de sua casa e dividiu por 30, para calcular o consumo diário. Para calcular o seu consumo diário, dividiu o valor pelo número de pessoas da casa. 


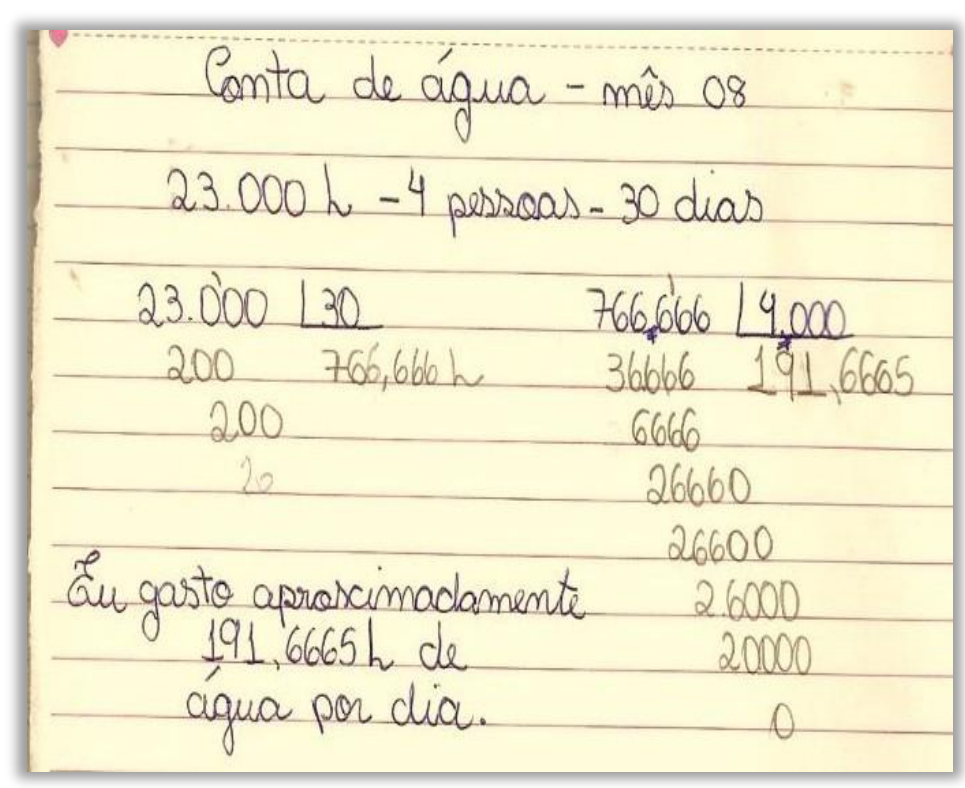

Figura 3: Estratégia de medição do consumo diário de água feita por A15

Observa-se, na Interação 7, que os atos dialógicos estão presentes no intuito de elucidar as perspectivas reconhecidas pela turma. 0 estabelecer contato acontece quando os estudantes prestam atenção na perspectiva socializada da média refletindo sobre ela. Eles percebem essa perspectiva usada por A15 e A17, reconhecendo-a, e procuram examinar a ideia matemática que foi verbalizada. Eles posicionam-se apresentando argumentos que ajudam A15 e a17 a esclarecer suas dúvidas.

Os estudantes, ao pensarem alto, expressam suas ideias, examinam e desenvolvem os pressupostos de como estão entendendo a questão. A avaliação acontece quando refletem sobre a aplicabilidade do uso da média aritmética, para resolver o problema em estudo, e concluíram que não foi a estratégia mais indicada e que A15 e A17 usaram critérios diferentes para a média. A17 avalia seus cálculos entendendo que o que achou foi a média das casas, e não a dos consumidores. Notamos um apoio verbal construtivo durante os discursos.

Conforme ressaltam Alrø e Skovsmose (2010), num processo investigativo, o certo ou errado não devem prevalecer, pois estudantes e professor devem avaliar as perspectivas. Os estudantes conjuntamente refletem sobre o equívoco de A15 e A17, no que tange à aplicabilidade do uso da média aritmética para resolver o problema em estudo. $O$ diálogo os levou a concluir que A15 e A17 não responderam satisfatoriamente à indagação - Eu sou gastão de água? —, uma vez que se encontrou o consumo médio e não o individual.

No final das discussões, os estudantes reconheceram ser gastões de água e que 
precisavam mudar seus hábitos em relação ao uso diário da água. Ao usar as ferramentas matemáticas para calcular o consumo de água, diagnosticaram o seu uso de forma irracional desenvolvendo competências democráticas ao refletirem que suas ações refletem na globalidade. Essa foi a primeira atividade de modelagem desenvolvida com esses estudantes.

\section{Considerações}

A Modelagem Matemática na perspectiva sociocrítica favoreceu a comunicação dialógica com atos da fala que constituem o Modelo $\mathrm{Cl}$. Professor e estudantes trabalharam de forma colaborativa desde 0 início da atividade de modelagem quando esses expressaram suas preocupações com a escassez de água. Foi também por meio do diálogo que as discussões chegaram ao consumo de água local dando suporte ao pesquisador para elaborar o desafio: Eu sou gastão de água?

O ambiente de aprendizagem marcado pelos atos dialógicos do Modelo $\mathrm{Cl}$ permitiu que os estudantes discutissem as estratégias usadas na medição e explorassem as variáveis matemáticas dos modelos, quando tiveram de fazer arredondamentos com as unidades de tempo, usar a internet para calcular o consumo das descargas ou usar a média para uma questão individual e descobrir que poderiam usar a Matemática de várias formas para abordar um problema. Essas são características peculiar do cenário investigativo bem diferentes do paradigma do exercício.

A Modelagem Matemática na perspectiva sociocrítica aproximou a Educação Matemática escolar ao contexto social dos estudantes, mas também estreitou a relação deles com os recursos do nosso tempo. Observamos que a autonomia dada aos estudantes para medir o consumo da água os levaram a uma postura de pesquisadores, usando como instrumentos a internet, o celular, baldes, garrafas PET, a conta de água e artefatos da nossa sociedade.

A comunicação dialógica acontece quando a natureza da prática pedagógica é investigativa dando oportunidade para os estudantes discursarem suas perspectivas num ambiente democrático, opinando e ouvindo a opinião dos outros. Assim, o professor atento aos posicionamentos de suas falas, assume o papel de mediador aprendendo e fazendo com que eles também adquirem novos conhecimentos.

O trabalho é um aporte de como a atividade de Modelagem na perspectiva sociocrítica 
facilita a comunicação dialógica na aula de Matemática, favorecendo os processos de ensino e de aprendizagem e a formação cidadã dos estudantes. A partir do exposto, muitas outras possibilidades podem ser exploradas pelos professores viabilizando uma maior qualidade na forma de ensinar a Matemática no âmbito escolar.

\section{Referências}

ALRØ, Helle; SKOVSMOSE, Ole. Diálogo e aprendizagem em Educação Matemática. Tradução de Orlando de Andrade Figueiredo. 2. ed. Belo Horizonte: Autêntica, 2010.

ARAÚJO, Jussara de Loiola. Relações entre matemática e realidade em algumas perspectivas de Modelagem Matemática na educação matemática. In: BARBOSA, Jonei Cerqueira; CALDEIRA; Ademir Donizete; Araújo, Jussara de Loiola (Org.). Modelagem matemática na educação matemática brasileira: pesquisas e práticas educacionais. Recife: SBEM, 2007, p. 17-32.

BARBOSA, Jonei Cerqueira. A prática dos alunos no ambiente de Modelagem Matemática: 0 esboço de um framework. In: BARBOSA, Jonei Cerqueira; CALDEIRA; Ademir Donizete; Araújo, Jussara de Loiola (Org.). Modelagem matemática na educação matemática brasileira: pesquisas e práticas educacionais. Recife: SBEM, 2007, p. 161-174.

BARBOSA, Jonei Cerqueira. As relações dos professores com a Modelagem Matemática. In: ENCONTRO NACIONAL DE EDUCAÇÃO MATEMÁTICA, 8, 2004, Recife. Anais do VIII ENEM — Educação Matemática: um compromisso social. Recife: SBEM, 2004b, p. 1-11.

BARBOSA, Jonei Cerqueira. Modelagem Matemática e a perspectiva sócio-crítica. In: II SEMINÁRIO INTERNACIONAL DE PESQUISAS EM EDUCAÇÃO MATEMÁTICA, 2003, Santos. Resumos do II SIPEM. Santos: SBEM, 2003, p. 140.

BARBOSA, Jonei Cerqueira. Modelagem matemática: O que é? Por quê? Como? Veritati, n. 4, p. 73-80, 2004a.

BIEMBENGUT, Maria Salett. Modelagem matemática no ensino. 3. ed. São Paulo: Contexto, 2003.

D'AMBROSIO, Ubiratan. Da realidade à ação: reflexões sobre Educação e Matemática. Campinas: Summus / UNICAMP, 1986.

FORNER, Régis; MALHEIROS, Ana Paula dos Santos. Modelagem e o currículo paulista: entre imposições, cobranças veladas e insubordinações criativas. Revista Paranaense de Educação Matemática, Campo Mourão, v. 8, n. 17, p. 519-545, jul./dez. 2019.

JACOBINI, Otávio Roberto; WODEWOTZKI, Maria Lúcia. Uma reflexão sobre Modelagem Matemática no contexto da Educação Matemática Crítica. Bolema, Rio Claro, v. 19, n. 25, p. 71 88, jan.jjun. 2006.

KAISER, Gabriele; SRIRAMAN, Bharath. A global survey of international perspectives on modelling in Mathematics Education. Zentralblatt fur Didaktik der Mathematik, v. 38, n.3, p. 302-310, jun. 2006. 
MINAYO, Maria Cecília de Souza. et al. (Org.). Pesquisa social: teoria, método e criatividade. 22. ed. Petrópolis: Vozes, 2003.

SILVA, Cíntia da; KATO, Lilian Akemi. Quais elementos caracterizam uma atividade de Modelagem Matemática na perspectiva sociocrítica. Bolema, Rio Claro, v. 26, n. 43, p. 817-838, ago. 2012.

SKOVSMOSE, Ole. Um convite à Educação Matemática Crítica. Tradução de Orlando de Andrade Figueiredo Campinas: Papirus, 2014. 